\title{
Office-based spirometry to stratify the risk of postoperative complications
}

\author{
Shigeki Suzuki ${ }^{1}$, Yusuke Takahashi ${ }^{1,2}$ \\ ${ }^{1}$ Department of General Thoracic Surgery, Sagamihara Kyodo Hospital, Sagamihara, Kanagawa, Japan; ${ }^{2}$ Department of General Thoracic Surgery, \\ Teikyo University School of Medicine, Itabashi, Tokyo, Japan \\ Correspondence to: Yusuke Takahashi, MD, PhD. Chief of General Thoracic Surgery, Sagamihara Kyodo Hospital, Associate Professor, General \\ Thoracic Surgery, Teikyo University, School of Medicine, 2-8-18 Hashimoto, Midori-ku, Sagamihara, Kanagawa 252-5188, Japan. \\ Email: yusuketakahashigts@gmail.com. \\ Comment on: Hudson JL, Bell JM, Crabtree TD, et al. Office-Based Spirometry: A New Model of Care in Preoperative Assessment for Low-Risk \\ Lung Resections. Ann Thorac Surg 2018;105:279-86.
}

Submitted Sep 29, 2018. Accepted for publication Oct 10, 2018.

doi: $10.21037 /$ atm.2018.10.25

View this article at: http://dx.doi.org/10.21037/atm.2018.10.25

Nowadays, lung cancer is the most common cause of cancer death in the world, and lung resection is recognized as the standard treatment for early-stage lung cancer (1). Since postoperative pulmonary complications are major driver of perioperative mortality, postoperative length of stay and rehospitalization (2-4), stratifying poor risk patients for pulmonary complications is critical issue (5-7).

With regard to the assessment of risk of postoperative complications following lung resection, spirometry and electrocardiography has been recommended by the American College of Chest Physicians, the British Thoracic Society and the European Society of Thoracic Surgeons (8-10). On spirometry, forced expiratory volume in one second (FEV1) and diffusing capacity of the lung for carbon monoxide (DLCO) are commonly measured to calculate predicted postoperative pulmonary function as well as to stratify risk for postoperative pulmonary complication.

Conventional laboratory spirometry (LS) is a standard tool to evaluate preoperative lung function in the world $(8,11,12)$. In previous literature, office-based spirometry (OS) is documented as a useful tool for screening of chronic obstructive pulmonary disease (COPD) (13-15). While OS can provides only FEV1 and forced vital capacity (FVC), OS has advantage of saving time and possibly expense in the preoperative evaluation of lung function in patients undergoing lung resection comparing to LS $(8,16)$. Furthermore, Puri et al. showed that OS-FEV1 was clinically comparable to formal LS values, and the sensitivity of OS for detecting the risk of complications was $100 \%$ and specificity was $93 \%$ in low risk patients undergoing lung resection (17). In this context, Hudson et al. hypothesized that OS can be used for evaluating operability for lung resection instead of LS in low risk patients. Thus, they investigated the safety of preoperative risk stratification for lung resection in this population (18).

The authors prospectively enrolled 66 patients undergoing lung resection who were considered as low-risk for cardiopulmonary complications in terms of performance status, exercise tolerance function, surgical procedure and comorbidities in their study (18). Finally, 52 propensity score-matched pairs who received preoperative LS or OS were compared and they showed that patients received preoperative OS had experienced similar major morbidity to those who received preoperative LS. They concluded that we can adequately and safely evaluate risk of postoperative pulmonary complications using preoperative OS without formal LS, with significant cost savings ( $\$ 38,000$ per year). Clinical usefulness of OS to assess FEV1 before lung resection has already been reported in a small cohort (17), however, this paper by Hudson et al. which mainly focused on major postoperative complications is more practical (18).

Many clinicians may be interested in whether OS can be used in moderate or higher risk patients as preoperative assessment instead of formal LS; however, this is still unknown because the authors enrolled only low risk patients anticipated few postoperative mortality and few complications in this study. For the low risk patients who passed their strict inclusion and exclusion criteria in their 
study, even OS may not be required and blood gas analysis may be sufficient.

Moreover, as for the surgical procedure, patients underwent sublobar resection; wedge resection or segmentectomy were included in this study. Almost two third patients had undergone sublobar resection even after propensity score matching. Sublobar resection is often selected as a limited resection for high risk patients who cannot tolerate lobectomy to avoid risk for postoperative complications in our daily practice. It may cause very few complications, so that there was not any difference in postoperative events between OS-group and LS-group. On the other hand, pneumonectomy which may often cause some complications was excluded in this study. It might have been more useful for us if sublobar resection had been omitted as well.

As mentioned above, their paper has some parts of consideration, but what is clinically significant in this study is that they suggested that preoperative LS which has been routinely used in the most cases in our daily practice may be unnecessary at least in the highly selected low risk patients and using preoperative OS may result in reducing the medical expense. Some preoperative evaluations are often time- and cost-consuming and may not be mandatory in some setting. To omit the unnecessary examinations has benefit for both patients and physicians.

In summary, their finding could provide rationale for future prospective studies to compare predictive ability of postoperative pulmonary complications between OS and LS. Furthermore, OS needs to be assessed in patients with moderate or higher risk in large-scale cohort, possibly in prospective study. Widely use of preoperative OS may contribute to medical economy in near future.

\section{Acknowledgements}

We thank Dr. Wymen Chen and Dr. Rafael Rosell for the invitation.

\section{Footnote}

Conflicts of Interest: The authors have no conflicts of interest to declare.

\section{References}

1. Jemal A, Bray F, Center MM, et al. Global cancer statistics. CA Cancer J Clin 2011;61:69-90.
2. Agostini P, Cieslik H, Rathinam S, et al. Postoperative pulmonary complications following thoracic surgery: are there any modifiable risk factors? Thorax 2010;65:815-8.

3. Qaseem A, Snow V, Fitterman N, et al. Risk assessment for and strategies to reduce perioperative pulmonary complications for patients undergoing noncardiothoracic surgery: a guideline from the American College of Physicians. Ann Intern Med 2006;144:575-80.

4. McAlister FA, Bertsch K, Man J, et al. Incidence of and risk factors for pulmonary complications after nonthoracic surgery. Am J Respir Crit Care Med 2005;171:514-7.

5. Taylor LJ, Julliard WA, Maloney JD. Predictive value of pulmonary function measures for short-term outcomes following lung resection: analysis of a single high-volume institution. J Thorac Dis 2018;10:1072-6.

6. Pforr A, Pagès PB, Baste JM, et al.; Epithor Project French Society of Thoracic and Cardiovascular Surgery. A Predictive Score for Bronchopleural Fistula Established Using the French Database Epithor. Ann Thorac Surg 2016;101:287-93.

7. Takahashi Y, Matsuda M, Aoki S, et al. Qualitive analysis of preoperative high-resolution computed tomography:risk factors for pulmonary complications after major lung resection. Ann Thorac Surg 2016;101:1068-74.

8. Brunelli A, Kim AW, Berger KI, et al. Physiologic evaluation of the patient with lung cancer being considered for resectional surgery: diagnosis and management of lung cancer, 3rd ed: American College of Chest Physicians evidence-based clinical practice guidelines. Chest 2013;143:e166S-90S.

9. British Thoracic Society; Society of Cardiothoracic Surgeons of Great Britain and Ireland Working Party. BTS guidelines:guidelines on the selection of patients with lung cancer for surgery. Thorax 2001;56:89-108.

10. Brunelli A, Charloux A, Bolliger CT, et al. ERS/ESTS clinical guidelines on fitness for radical therapy in lung cancer patients (surgery and chemo-radiotherapy). Eur Respir J 2009;34:17-41.

11. Benattia A, Debeaumont D, Guyader V, et al. Physiologic assessment before video thoracoscopic resection for lung cancer in patients with abnormal pulmonary function. J Thorac Dis 2016;8:1170-8.

12. Ferguson MK, Watson S, Johnson E, et al. Predicted postoperative lung function is associated with all-cause long-term mortality after major lung resection for cancer. Eur J Cardiothorac Surg 2014;45:660-4.

13. Yawn BP, Duvall K, Peabody J, et al. The impact of screening tools on diagnosis of chronic obstructive 
pulmonary disease in primary care. Am J Prev Med 2014;47:563-75.

14. Johnson JD, Theurer WM. A stepwise approach to the interpretation of pulmonary function tests. Am Fam Physician 2014;89:359-66.

15. Bambra G, Jalota L, Kapoor C, et al. Office spirometry correlates with laboratory spirometry in patients with symptomatic asthma and COPD. Clin Respir J 2017;11:805-11.

16. Schoh RJ, Fero LJ, Shapiro H, et al. Performance of a new

Cite this article as: Suzuki S, Takahashi Y. Office-based spirometry to stratify the risk of postoperative complications. Ann Transl Med 2018;6(Suppl 1):S59. doi: 10.21037/ atm.2018.10.25 screening spirometer at a community health fair. Respir Care 2002;47:1150-7.

17. Puri V, Zoole JB, Musick J, et al. Handheld office-based spirometry versus laboratory spirometry in low-risk patients undergoing lung resection. Innovations (Phila) 2011;6:257-61.

18. Hudson JL, Bell JM, Crabtree TD, et al. Office-Based Spirometry: A New Model of Care in Preoperative Assessment for Low-Risk Lung Resections. Ann Thorac Surg 2018;105:279-86. 